\title{
ANALISIS KINERJA KEUANGANDENGAN PENDEKATAN EVA (STUDI KASUS : PT. SMARTFREN TELECOM, TBK PERIODE 2013-2015)
}

\author{
Ratna Kurnia Sari \\ Email :ratna.rus@bsi.ac.id \\ Program Studi Komputerisasi Akuntansi AMIK BSI Tegal \\ Jl. Sipelem No.22 Tegal, Indonesia
}

\begin{abstract}
The most important factor to be able to see the development of a Telecommunications company lies in its financial elements, because of these elements can be evaluated whether the policies adopted a company is correct or not, given the complexity of problems that can lead to bankruptcy due to the number of companies that ultimately out of business due to financial factors not healthy. While the goal to be achieved in this research is to know the financial performance of PT. Smartfren Telecom, Tbk reviewed based on the EVA approach.The data analysis method used here refers to a comparative descriptive analysis, in which the financial statements will be analyzed in terms of NOPAT, WACC, Invested Capital, Capital Charges and EVA in order to obtain a comparison of the results in each year, so that it will show the financial and performance levels of the company. While the data source used in this study is secondary data in the form of corporate financial statement documents from 2013 to 2015 obtained from the website of PT. Smartfren Telecom, Tbk is www.smartfren.com.The results obtained are that the largest EVA value at PT. Smartfren Telecom, Tbk occurs in 2015. This is due to the NOPAT value that is greater than the previous year and its Capital Charge value is also greater than the other period. From here it can also be seen that the value of EVA $<0$ where it shows no economic value-added for the company, so get negative results. And if this happens continuously, it will affect the creditors and shareholders to invest.
\end{abstract}

Keywords: financial performance, economic value added, telecommunication company

\section{Pendahuluan}

Subsektor industri Telekomunikasi memiliki peranan penting dalam pertumbuhan nilai Produk Domestik Bruto (PDB) di Indonesia, hal ini disebabkan oleh sektor industri telekomunikasi Indonesia yang berkembang dari tahun ke tahun. Ini bisa dilihat dari kondisi perekonomian yang tumbuh pesat dan mengharuskan perusahaan-perusahaan Telekomunikasi menjalankan usaha bisnisnya secara efektif dan efisien.

Faktor terpenting untuk dapat melihat perkembangan suatu perusahaan Telekomunikasi terletak pada unsur keuangannya, karena dari unsur tersebut dapat dievaluasi apakah kebijakan yang ditempuh suatu perusahaan sudah tepat atau belum, mengingat begitu kompleksnya permasalahan yang dapat menyebabkan kebangkrutan dikarenakan banyaknya perusahaan yang akhirnya gulung tikar karena faktor keuangan yang tidak sehat. Dengan perencanaan keuangan yang baik akan memberi manfaat bagi perusahaan yaitu perusahaan dapat memantau pemasukan dan pengeluaran yang dimiliki. Dalam hal ini perusahaan dapat mengetahui tindakan apa yang harus dilakukan untuk memperoleh keuntungan dan tindakan apa yang tidak perlu dilakukan apabila merugikan perusahaan. (Hanafi, 2004:52) ${ }^{[1]}$

Saat ini kinerja sebuah perusahaan lebih banyak diukur berdasarkan rasio-rasio keuangan selama satu periode tertentu. Di mana pengukuran berdasarkan rasio keuangan tersebut seringkali kurang mencerminkan kinerja yang sebenarnya sehingga perusahaan terlihat baik dan meningkat, berlawanan dengan yang sebenarnya yaitu kinerja tidak mengalami peningkatan dan bahkan menurun. Setelah penilaian kinerja manajemen perusahaan dengan rasio-rasio keuangan mengalami kejenuhan, maka diperlukan suatu alat ukur kinerja yang menunjukkan prestasi manajemen sebenarnya yang mampu mendorong aktivitas atau strategi yang mampu menambah nilai ekonomis (value added activities) dan menghapuskan 
aktivitas yang merusak nilai (non-value added activities). Dalam hal ini, Economic Value Added (EVA) sangat relevan karena EVA dapat mengukur kinerja (prestasi) manajemen berdasarkan besar kecilnya nilai tambah ekonomis yang diciptakan oleh perusahaan sebagai akibat dari aktivitas yang dijalankan selama periode tertentu.

Tujuan yang ingin dicapai dalam penelitian ini adalah untuk mengetahui kinerja keuangan PT. Smartfren Telecom, Tbk yang ditinjau berdasarkan pendekatanEVA.

\section{Metode Penelitian}

\section{A. Jenis Penelitian}

Jenis penelitian yang digunakan berupa penelitian deskriptif komparatif, yaitu dengan meneliti laporan keuangan pertahun dengan mengunakan analisis EVA pada laporan keuangan lalu dibandingkan dengan laporan keuangan lainnya sehingga dapat diketahui tingkat kinerja keuangan pada PT. Smartfren Telecom, Tbk.

B. Jenis dan Sumber Data

Menurut Soeratno (2008:67) ${ }^{[4]}$, jenis data dapat dibedakan menjadi dua, yaitu :

1) Data kualitatif, merupakan data yang tidak dapat diukur dalam skala numerik atau data yang disajikan secara deskriptif atau yang berbentuk uraian.

2) Data kuantitatif, merupakan data yang disajikan dalam bentuk skala numerik (angka-angka), namun dalam statistik semua data harus dalam bentuk angka, maka data kulitatif umumnya dikuatitatifkan agar dapat diproses.

Dalam penelitian ini jenis data yang digunakan adalah data kualitatif yaitu profil perusahaan dan data kuantitatif yaitu laporan keuangan tahun 2013-2015.

Sedangkan sumber data menurut Kuncoro $(2008: 127)^{[5]}$, dibedakan menjadi dua,yaitu :

\section{1) Data primer}

Sumber data penelitian yang diperoleh secara langsung dari sumber asli (tidak melalui media perantara).

2) Data Sekunder

Sumber data penelitian yang diperoleh secara tidak langsung memalui perantara (diperoleh dan dicatat oleh pihak lain).

Sumber data yang digunakan dalam penelitian ini adalah data sekunder yang berupa dokumen laporan keuangan perusahaan dari tahun 2013 sampai 2015 yang diperoleh dari website PT. Smartfren Telecom, Tbk yaitu www.smartfren.com ${ }^{[6 .}$

\section{Hasil Dan Pembahasan}

A. Hasil Penelitian

Tabel 1.Hasil Perhitungan NOPAT

\begin{tabular}{|c|c|c|c|}
\hline Tahun & EAT & $\begin{array}{c}\text { Biaya } \\
\text { Bunga }\end{array}$ & NOPAT \\
\hline 2013 & $(2.534 .463)$ & 13.620 & $(2.520 .843)$ \\
\hline 2014 & $(1.379 .003)$ & 30.112 & $(1.348 .891)$ \\
\hline 2015 & $(1.565 .410)$ & 25.781 & $(1.539 .629)$ \\
\hline
\end{tabular}

Tabel 2. Hasil Perhitungan Invested Capital (IC)

\begin{tabular}{|c|c|c|c|}
\hline $\begin{array}{c}\text { Tahu } \\
\mathbf{n}\end{array}$ & $\begin{array}{c}\text { Total } \\
\text { Hutang } \\
\text { dan } \\
\text { Ekuitas }\end{array}$ & $\begin{array}{c}\text { Pinjama } \\
\text { n Jangka } \\
\text { Pendek }\end{array}$ & $\begin{array}{c}\text { Investe } \\
\mathbf{d} \\
\text { Capital }\end{array}$ \\
\hline 2013 & $\begin{array}{c}15.866 .49 \\
3\end{array}$ & 5.539 .550 & $\begin{array}{c}10.326 .9 \\
43\end{array}$ \\
\hline 2014 & 17.743 .60 & 6.552 .092 & $\begin{array}{c}11.191 .5 \\
15\end{array}$ \\
\hline 2015 & $\begin{array}{c}20.705 .91 \\
3\end{array}$ & 4.159 .191 & $\begin{array}{c}16.546 .7 \\
22\end{array}$ \\
\hline
\end{tabular}

Tabel 3. Hasil Perhitungan WACC

\begin{tabular}{|c|c|c|c|}
\hline Keterangan & 2013 & 2014 & 2015 \\
\hline $\begin{array}{l}\text { Tingkat Modal } \\
\text { dari Hutang } \\
\text { (D) }\end{array}$ & $\begin{array}{c}80,78 \\
\%\end{array}$ & $\begin{array}{c}77,42 \\
\%\end{array}$ & $\begin{array}{c}66,93 \\
\%\end{array}$ \\
\hline $\begin{array}{l}\text { Cost of Debt } \\
(r d)\end{array}$ & $0,11 \%$ & $\begin{array}{c}0,22 \\
\%\end{array}$ & $0,19 \%$ \\
\hline $1-$ Tax & $\begin{array}{c}106,40 \\
\%\end{array}$ & $\begin{array}{l}101 \\
90 \%\end{array}$ & $122 \%$ \\
\hline $\begin{array}{l}\text { Tingkat Modal } \\
\text { dari Ekuitas } \\
\text { (E) }\end{array}$ & $\begin{array}{c}19,22 \\
\%\end{array}$ & $\begin{array}{c}22, \\
31 \%\end{array}$ & $\begin{array}{c}33,08 \\
\%\end{array}$ \\
\hline $\begin{array}{l}\text { Cost of Equity } \\
\text { (re) }\end{array}$ & $\begin{array}{c}(74,02 \\
\%)\end{array}$ & $\begin{array}{c}(21, \\
44 \%)\end{array}$ & $\begin{array}{c}(27,57 \\
\%)\end{array}$ \\
\hline WACC & $\begin{array}{c}(14,14 \\
\%)\end{array}$ & $\begin{array}{c}(4,61 \\
\%)\end{array}$ & $\begin{array}{c}(8,97 \\
\%)\end{array}$ \\
\hline
\end{tabular}


Tabel 4. Hasil Perhitungan Capital Charges

\begin{tabular}{|c|c|c|c|}
\hline $\begin{array}{c}\text { Tahu } \\
\mathbf{n}\end{array}$ & $\begin{array}{c}\text { WAC } \\
\text { C }\end{array}$ & $\begin{array}{c}\text { Invested } \\
\text { Capital }\end{array}$ & $\begin{array}{c}\text { Capital } \\
\text { Charges }\end{array}$ \\
\hline 2013 & $(14,14$ & 10.326 .94 & $(1.459 .713,39$ \\
& $\%)$ & 3 & ) \\
\hline 2014 & $(4,58$ & 11.191 .51 & $(512.683,30)$ \\
& $\%)$ & 5 & \\
\hline 2015 & $(8,97$ & 16.546 .72 & $(1.483 .910,03$ \\
& $\%)$ & 2 & ) \\
\hline
\end{tabular}

Tabel 6. Hasil Perhitungan EVA

\begin{tabular}{|c|c|c|c|}
\hline $\begin{array}{c}\text { Tahu } \\
\mathbf{n}\end{array}$ & NOPAT & $\begin{array}{c}\text { Capital } \\
\text { Charges }\end{array}$ & EVA \\
\hline 2013 & $\begin{array}{c}(2.520 .84 \\
3)\end{array}$ & $\begin{array}{c}(1.459 .713,3 \\
9)\end{array}$ & $\begin{array}{c}(1.061 .13 \\
0)\end{array}$ \\
\hline 2014 & $(1.348 .89$ & $(512.683,30$ & $(836.208)$ \\
& $1)$ & ) & \\
\hline 2015 & $\begin{array}{c}(1.539 .62 \\
9)\end{array}$ & $\begin{array}{c}(1.483 .910,0 \\
3)\end{array}$ & $(55.719)$ \\
\hline
\end{tabular}

\section{B. Pembahasan}

Berdasarkan tabel di atas, bisa dilihat bahwa nilai EVA terbesar pada PT. Smartfren Telecom, Tbk terjadi pada tahun 2015. Hal ini disebabkan oleh nilai NOPAT yang lebih besar dari tahun sebelumnya dan nilai Capital Charge-nya juga lebih besar dibandingkan dengan periode yang lain. Dari sini juga bisa dilihat bahwa nilai EVA $<0$ di mana menunjukkan tidak terjadi nilai tambah ekonomis bagi perusahaan, sehingga mendapatkan hasil negatif. Dan apabila hal ini terjadi terus menerus, maka akan berpengaruh pada para kreditur dan pemegang saham untuk menanamkan modalnya.

\section{Kesimpulan}

Berdasarkan hasil penelitian dan analisis data yang telah dilakukan, maka dapat diambil kesimpulan bahwa nilai EVA pada PT. Smartfren Telecom, Tbk dari tahun 2013-2015 dinyatakan kurang baik.Hal ini menunjukkan bahwa tingkat pengembalian investasi yang dihasilkan perusahaan lebih rendah dari biaya modalnya. Keaadaan ini juga menunjukan bahwa kinerja keuangan PT Smartfren Telecom,Tbk tidak terjadi nilai tambah ekonomis bagi perusahaan. Sehingga dapat berpengaruh pada para kreditur dan pemegang saham yang telah menanamkan modalnya pada perusahaan tersebut.

\section{Daftar Pustaka}

[1] Hanafi, Mamduh M, 2005, Analisis Laporan Keuangan, Penerbit.

[2] Munawir, 2010. Analisis Laporan Keuangan. Liberty. Yogyakarta

[3]Kasmir, 2008, Analisis Laporan Keuangan, edisi pertama, cetakan pertama, Penerbit : Rajawali Pers, Jakarta

[4] Soeratno. 2008. Metode Penelitian Untuk Ekonomi dan Bisnis. Andi, Yogyakarta.

[5] Kuncoro, Mudrajad. 2008. Metode Riset Untuk Bisnis dan Ekonomi. Erlangga, Jakarta.

[6] Laporan Keuangan PT. Smartfren Telecom, Tbk. 